\title{
Relationship between Anxiety, Self-Confidence, and Evaluation of Coaching Behaviors
}

\author{
Laura J. Kenow \\ Linfield College \\ Jean M. Williams \\ University of Arizona
}

Follow this and additional works at: https://digitalcommons.linfield.edu/hhpafac_pubs

Part of the Sports Sciences Commons

\section{DigitalCommons@Linfield Citation}

Kenow, Laura J. and Williams, Jean M., "Relationship between Anxiety, Self-Confidence, and Evaluation of Coaching Behaviors" (1992). Faculty Publications. Published Version. Submission 2.

https://digitalcommons.linfield.edu/hhpafac_pubs/2

This Published Version is protected by copyright and/or related rights. It is brought to you for free via open access, courtesy of DigitalCommons@Linfield, with permission from the rights-holder(s). Your use of this Published Version must comply with the Terms of Use for material posted in DigitalCommons@Linfield, or with other stated terms (such as a Creative Commons license) indicated in the record and/or on the work itself. For more information, or if you have questions about permitted uses, please contact digitalcommons@linfield.edu. 


\title{
Relationship Between Anxiety, Self-Confidence, and Evaluation of Coaching Behaviors
}

\section{Laura J. Kenow Linfield College}

\author{
Jean M. Williams \\ University of Arizona
}

\begin{abstract}
Two experiments examined Smoll and Smith's (1989) model of leadership behaviors in sport. The coaching behaviors of a male head coach of a collegiate women's basketball team ( $n=11$ players) were examined. The data supported competitive trait anxiety as an individual-difference variable that mediates athletes' perception and evaluation of coaching behaviors. There also was support for adding athletes' state cognitive anxiety, state selfconfidence, and perception of the coach's cognitive anxiety to the model as individual-difference variables. Athletes who scored high in trait anxiety $(p<.001)$ and state cognitive anxiety $(p<.05)$ and low in state self-confidence $(p<.05)$, and athletes who perceived the coach as high in state cognitive anxiety $(p<.001)$, evaluated coaching behavior more negatively. Game outcome may influence the effect of self-confidence in mediating athletes' perception and evaluation of coaching behaviors. Additionally, athletes perceived several specific coaching behaviors more negatively than did the coach, and athletes drastically overestimated their coach's self-reported pregame cognitive and somatic anxiety and underestimated his self-confidence. Overall, the results suggest that coaches should be more supportive and less negative with high anxious and low self-confident athletes.
\end{abstract}

Guiding a team to victory is a goal for most coaches. Consequently, coaches try to behave in ways they feel will be effective in helping their athletes achieve peak performance. Unfortunately, coaches may not be entirely aware of their behaviors, much less the effect these behaviors have on athletes. Smith, Smoll, and Curtis (1978), in a study of Little League baseball coaches, found that coaches actually had little awareness of how frequently they behaved in various ways. Coaches felt they were nonpunitive and administered positive reinforcement and encouragement frequently, but players' ratings of their coach suggested otherwise.

Smoll and Smith's (1989) model of leadership behaviors in sport provides a foundation for examining coaching behaviors and the factors influencing athletes' perceptions and evaluations of these behaviors (see Figure 1). The central process

L.J. Kenow is with the Dept. of Health, Human Performance and Athletics at Linfield College, McMinnville, OR 97128. J.M. Williams is with the Department of Exercise and Sport Sciences at the University of Arizona, Tucson, AZ 85721. 
Figure 1 - Model of coaching behaviors, their antecedents, and their effects, with hypothesized relations among situational, cognitive, behavioral, and individual difference variables (Smoll \& Smith, 1989).
Perceived coaching norms

Valence of coach behaviors

Sport-specific achievement motives

Competitive trait anxiety

General self-esteem

Athletic self-esteem

Sex

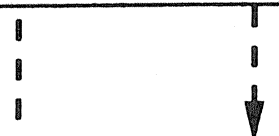

\section{COACH BEHAVIORS}
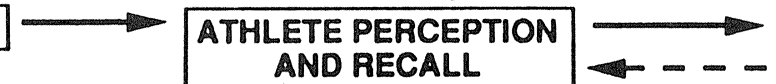

ATHLETES' EVALUATIVE

1

1

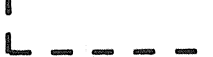

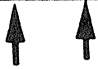

AND RECALL

1

- -

of

$\begin{aligned} & L-2- \\ & --\end{aligned}-\left\{\begin{array}{l}\text { Coach Porception of } \\ \text { Athletes' Attitudes }\end{array}\right.$

I

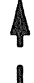

1

\section{Situational Factors}

Nature of the sport

Level of competition (e.g., interscholastic vs. recreational)

Practice vs. game

Previous success/failure (e.g., season record to date)

Present game/practice outcomes

Intrateam attraction 
of the model is defined with solid arrows. That is, the coach behaves in a certain way; the athletes perceive and recall these behaviors; and based on this perception and recall, the athletes have an evaluative reaction to the coach's behavior. The model also includes situational factors, coach and athlete individual-difference variables, and the coach's perception of athletes' attitudes. The mediating effects of the different variables are defined by dashed arrows. Thus, the ultimate effectiveness of coaching behaviors is a result of many complex interactions of the mediating variables.

Included among the athlete individual-difference variables are competitive trait anxiety and self-esteem (general and athletic). Currently, no empirical evidence exists to support the competitive trait anxiety aspect of the model. In one of the few studies to address the mediating effects of athletic self-esteem, Smith and Smoll (1990) found that low self-esteem children, as compared to children with moderate and high levels of self-esteem, responded more positively to highly supportive and highly instructive coaches and more negatively to coaches who were low in these behaviors.

We propose that state somatic and cognitive anxiety and state self-confidence may also be mediating variables in athletes' perception and evaluation of coaching behaviors. Athletic self-confidence, defined as the degree of certainty athletes possess concerning their ability to be successful in sport (Vealey, 1986), is a concept related to an individual's athletic self-esteem (feelings of self-worth in an athletic setting). Therefore, individual differences in state self-confidence may also play a mediating role in athletes' perception and evaluation of coaching behaviors.

Cognitive state anxiety, characterized by worry and negative expectations about success, and somatic state anxiety, characterized by physiological responses resulting from autonomic arousal, are related to competitive trait anxiety. Specifically, high trait-anxious individuals may respond to threatening situations with more intense levels of state anxiety (Martens, Vealey, \& Burton, 1990). There is merit, therefore, in examining the mediating effects of both state and trait anxiety when assessing perception of coaching behaviors.

Coaches, in the competitive setting, engage in a wide variety of behaviors. The behaviors that are affected by the mediating variables of Smoll and Smith's (1989) model have not been identified. However, some important areas of coaching behavior to examine can be derived from previous research. Percival (1971), in an evaluation of responses from 382 athletes representing 24 different sports at all competitive levels, reported a predominance of athletes' dissatisfaction with and negative reaction to their coaches. Several specific areas of criticism were cited, including coaches' mannerisms, emotionalism, verbal presentation, and tension level. Perhaps differences in anxiety and self-confidence in athletes and coaches play a role in how athletes evaluate and respond to these aspects of coaching behavior.

Several studies have documented that athletes are somewhat accurate in their ability to predict their coach's anxiety levels (Hanson \& Gould, 1988; KjossHansen, 1983; Martens, Rivkin, \& Burton, 1980). It is unknown, however, if the coach's anxiety level, as perceived by the players, correlates with the way players react to coaching behaviors.

Therefore, the purpose of the present studies was to test, within a specific team, the competitive trait anxiety aspect of Smoll and Smith's (1989) model of 
leadership behaviors in sport. An additional purpose was to examine whether or not athletes' state anxiety and self-confidence and athletes' perceptions of their coach's state anxiety and self-confidence are individual-difference variables that potentially should be added to the model as mediators of athletes' perception and evaluation of coaching behaviors.

\section{Study 1}

This study examined possible relationships between anxiety, self-confidence, and evaluation of coaching behavior in the hypothetical, generalized setting of playing one of the top three teams in the athletic conference. Subjects were instructed to respond as they felt they typically would when playing one of these teams. Within this context, this study examined the relationship between athletes' perceptions of their coach's behavior and the coach's perception of his own behavior, as well as the relationship between athletes' trait anxiety, generalized state anxiety, self-confidence, and evaluation of coaching behaviors. It was hypothesized that athletes perceive coaching behaviors differently than does the coach and that high-anxious and low self-confident athletes evaluate coaching behaviors more negatively than do low-anxious and high self-confident athletes.

\section{Methods}

Subjects. Female collegiate basketball players $(N=11)$ from a southwest NCAA Division III program and their male head coach participated in the study during the last month of their season. The team was ranked in the top three in its conference. Subjects participated voluntarily and with the assurance of anonymity. Athletes were contacted only after obtaining the coach's permission.

Anxiety Measures. The Sport Competition Anxiety Test (SCAT; Martens, 1977) assessed competitive trait anxiety. General state anxiety and self-confidence were measured using the Competitive State Anxiety Inventory-2 (CSAI-2; Martens et al., 1990). This instrument assessed both somatic and cognitive anxiety, as well as competitive self-confidence. The instructions for this instrument were modified to direct subjects to respond as if they were going to play one of the top three teams in their conference.

Coaching Behavior Questionnaire (CBQ). A 28-item questionnaire developed specifically for this study evaluated coaching behaviors that might occur when competing against one of the top three teams in the conference. A 4-point Likert scale ranging from strongly disagree (1) to strongly agree (4) was used to assess each individual item. Positively worded items (e.g., "criticism from my coach is done in a constructive manner') were reverse-weighted so that higher total scores on the CBQ reflected a more negative evaluation of the coach's game behaviors. Seven filler items were excluded from the scoring, resulting in a range of potential total scores from 21 to 84 .

Individual items and conceptual categories for the questionnaire were drawn from the coaching and sport psychology experience of the authors and from the findings of Percival (1971). The resulting individual items were modified based upon the critiques of six coaches. The coaching-behavior questions examined (a) athletes' opinions concerning the coach's ability to communicate (e.g., " before and during a game, my coach clearly communicates what he/she expects us to do," and "criticism from my coach is done in a constructive manner"'); (b) the 
confidence the coach displays in his or her players (e.g., "my coach displays confidence in me as a player'); (c) the coach's composure and emotional control (e.g., "my coach is appropriately composed and relaxed," and "my coach controls his/her emotions well during games"'); and (d) how the coach's arousal level and behavior affect the player (e.g., "my coach's behavior during a game makes me feel tight and tense," and "when my coach appears uptight, I don't play as well' '). The coach responded to the same items except the wording was modified (e.g., "my coach is appropriately composed and relaxed" was changed to "I am appropriately composed and relaxed'). Each behavioral category was assessed with three to seven items, with some items examining more than one area (e.g., "my coach shows support for me even when I make a mistake" taps into confidence, communication, and emotional control).

No pilot study was conducted on the questionnaire other than having it critiqued by six individuals, who had current or past coaching experience, to determine if the items were worded clearly and if they assessed behaviors believed to be important in coaching effectiveness. Because this was the first time the CBQ was used and because the multicomponent nature of many of its items would make quite arbitrary any decision to put the items into subscales, it was decided that the most beneficial scoring system would be to look at the total questionnaire score, as well as the scores on individual items, to assess the relationship between anxiety, self-confidence, and evaluation of coaching behaviors.

Procedure. Questionnaire packets and instructions for testing the athletes were mailed to an assistant coach, who then administered the questionnaires. To ensure confidentiality, each subject sealed her responses in an envelope, signed her name across the seal, and gave the envelope to the assistant coach, who mailed all responses back to one of the investigators.

Testing was conducted following a practice session during the last month of the season. There were no games 4 days before or 4 days after this testing session, in order to avoid potential distorting of responses due to a game or anticipated game. The coach completed his packet of questionnaires at the same time as the athletes, but in a separate location.

\section{Results and Discussion}

Table 1 contains the mean and standard deviation for each coach and athlete variable measured. Cronbach's alpha reliability for the CBQ was .90, indicating the acceptability of looking at a total CBQ score. Cronbach's alpha reliabilities for the cognitive anxiety (.79), somatic anxiety (.70), and self-confidence (.80) subscales of the CSAI-2, although slightly lower than those reported by Martens et al. (1990), were still high enough to justify the reliability of the CSAI-2 subscales with the modified directions used in the present study. Interscale correlations for the cognitive anxiety-somatic anxiety $(r=.23)$, cognitive anxiety-selfconfidence ( $r=-.63)$, and somatic anxiety-self-confidence $(r=-.15)$ subscales of the CSAI-2 were similar to the ranges reported by Martens et al. (1990).

Independent $t$ tests compared athletes' mean SCAT and CSAI-2 scores with norm values (Martens et al., 1990) in basketball player populations. No significant differences were found between the sample and the basketball norms, $t(10)<1.58$, $p>.05$. Hence, the anxiety and self-confidence responses of these athletes were comparable to what would be expected from the population as a whole. 
Table 1

\section{Means and Standard Deviations for Athlete and Coach Anxiety and CBQ Scores}

\begin{tabular}{|c|c|c|c|}
\hline \multirow[b]{2}{*}{ Variable } & \multicolumn{2}{|c|}{ Athletes' score } & \multirow{2}{*}{$\begin{array}{l}\text { Coach's } \\
\text { score }\end{array}$} \\
\hline & $M$ & $S D$ & \\
\hline Trait anxiety & 16.6 & 2.3 & 17 \\
\hline Typical cognitive anxiety & 19.6 & 3.5 & 17 \\
\hline Typical somatic anxiety & 17.8 & 3.2 & 15 \\
\hline Typical self-confidence & 26.7 & 4.1 & 27 \\
\hline $\mathrm{CBQ}$ & 53.2 & 11.1 & 52 \\
\hline
\end{tabular}

The means for the total CBQ scores for the athletes and the coach appeared to be similar (see Table 1). However, an analysis of the individual questions indicated a good deal of discrepancy between the athletes' and coach's perceptions of coaching behaviors. On four items, the coach's self-score deviated at least one standard deviation from the athletes' mean score, and five other items approached a discrepancy of one standard deviation. The four items over one standard deviation were "when I need it, my coach's tone of voice is soothing and reassuring," "my coach is appropriately composed and relaxed," "my coach gets more stressed out when we play the top teams in the conference," and "my coach's mannerisms and display of emotion contribute to me playing poorly."

On the first three of these items, the coach scored his behavior more positively (i.e., his tone of voice is soothing and reassuring; he is appropriately composed and relaxed; and he does not get more stressed out when playing the top teams) than the athletes did. These differences suggest the coach did not feel his mannerisms denoted being excessively stressed, although his athletes perceived him as being stressed.

Surprisingly, on the fourth item, the coach was more likely than the athletes to perceive that his mannerisms and display of emotions contributed to his athletes' playing poorly. Because the athletes were not asked why they responded the way they did, why this difference occurred is only conjecture. Possible explanations may be either that the athletes were so internal in their locus of control that they did not wish to attribute their poor performance to the coach's behavior or that the coach may be accepting too much of the responsibility for the way his athletes performed.

One interesting question regarding coaching behaviors is whose perceptions were the most accurate- the coach's or the athletes'? Although the present study did not record actual coaching behaviors, an earlier study by Smith et al. (1978) provides some insights regarding a potential answer to this question. Smith et al. found that correlations between observed coaching behaviors and coaches' self-perceptions of their behaviors were generally low and nonsignificant. In contrast, athletes' ratings of perceived coaching behaviors correlated much more highly with observed coaching behavior. Considering the discrepancy between the athletes and the coach in perceptions of coaching behaviors, 
future researchers may want to contrast self-perceptions with observation of actual coaching behaviors.

Correlational analyses determined if there was a relationship between the athletes' anxiety and confidence levels and the total score on the evaluation of coaching behaviors. High trait-anxious athletes perceived the coaching behaviors more negatively than did low trait-anxious athletes $(r=.85, p<.001)$. These results are not particularly surprising when taken into consideration with earlier studies. Athletes who score high in trait anxiety are more likely to perceive objectively nondangerous situations as threatening (Martens et al., 1990; Spielberger, 1966). Evidence also indicates that situations that involve threat to selfesteem or potential failure are perceived as powerful sources of threat (Spielberger, 1972). The competitive sport setting, by nature, involves potential failure, and the coach-athlete interaction can have a great impact on an athlete's selfesteem (Smith et al., 1978; Smoll, Smith, Barnett, \& Everett, 1991). Therefore, it is likely that high trait-anxious athletes construe game behaviors of the coach as threatening and, consequently, evaluate such behaviors negatively.

Athletes who score high in state self-confidence evaluated the coaching behaviors more positively $(r=-.59, p<.05)$. Research in the area of self-esteem and self-enhancement, concepts that are related to self-confidence, provides possible suggestions for why this occurred. Self-enhancement theory (Shrauger, 1975; Swann, Griffin, Predmore, \& Gaines, 1987; Tesser, 1988) states that people are motivated by a general desire to achieve and maintain positive self-regard. The need for self-enhancement is thought to be especially high in individuals who are low in self-esteem. Thus, if confidence and self-esteem are related concepts, it is possible that low-confident athletes may be more aware of and sensitive to the negative reactions, feedback, and behaviors of a coach than their confident teammates. As a result, low-confident athletes may perceive and evaluate more coaching behaviors negatively.

Brown, Collins, and Schmidt (1988) and Smith and Smoll (1990) suggested that individuals who are low in self-esteem may be more reliant on indirect measures of self-worth, such as those received through the feedback from others, to satisfy their self-enhancement needs. In a similar way, the low-confident athlete may rely on the coach's verbal and nonverbal feedback to assist in building confidence. If athletes' perception of the coach's behavior does not foster this confidence, they may evaluate this behavior negatively.

Regarding each athlete's perception of her typical levels of state anxiety prior to games against top opponents, athletes who scored high in cognitive anxiety evaluated coaching behaviors more negatively than did their low cognitive-anxious teammates $(r=.68, p<.05)$. In contrast, somatic anxiety did not correlate with the evaluation of coaching behavior $(r=16)$. Intuitively, this result makes sense because evaluation of coaching behaviors is a cognitive process. Therefore, the physiological responses reflected in somatic anxiety would not be related to the evaluation of coaching behaviors as much as would cognitive anxiety.

Gould, Petlichkoff, and Weinberg (1984) suggested that cognitive anxiety is linked to performance expectancies. That is, athletes who question their ability to meet the demands of the athletic situation will be higher in cognitive anxiety; athletes confident of their ability to meet the situational demands will be low in cognitive anxiety. Perhaps athletes who worry about their performance abili- 
ties may be more sensitive to subtleties in a coach's demeanor. This increased sensitivity and insecurity may influence high cognitive-anxious athletes to overexaggerate perceived negative mannerisms and feedback in a coach's behavior prior to or during competition. Thus, coaching behaviors that appear neutral or constructively critical to a moderate or low-anxious athlete may be interpreted negatively by the high-anxious athlete as a result of the self-doubt and worry already present.

The five individual items on the CBQ that correlated the strongest $(r=.66$ to .86) with athletes' cognitive anxiety offer some support for the preceding comments. Athletes who scored high in cognitive anxiety were more likely to report "my coach made me feel uptight," " my coach's behavior during the game made me worry about my performance," and "I got more nervous watching my coach on the sidelines than I did playing the game'" and less likely to report "before and during the game, my coach clearly communicated what he/she expected us to do," and "my coach used time-outs and halftime to build our confidence." The first four items on this list were also most highly correlated with self-confidence ( $r=-.66$ to -.89 ). This finding is not surprising considering that, although independent subcomponents, cognitive anxiety and self-confidence are correlated (Martens et al., 1990). Within the present study, cognitive anxiety and self-confidence correlated even more strongly ( $r=-.63)$ than Martens' normative data ( $r=-.48$, Martens et al., 1990).

These results emphasize the need for coaches to be aware of the anxiety and confidence levels of their individual athletes. Coaching behaviors that may be effective in informing, motivating, or leading the confident and low-anxious athlete may have the opposite effect on the low-confident and cognitively anxious athlete. Researchers, however, have found that coaches are not very accurate in predicting their athletes' state anxiety levels (Gould, Krane, \& Finch, 1990; Hanson \& Gould, 1988; Kjoss-Hansen, 1983; Martens et al., 1980). There may be merit in assessing what influences how effectively coaches estimate their players' anxiety and selfconfidence levels (particularly cognitive anxiety) and what interventions would be most effective in increasing the accuracy of coaches' perceptions.

\section{Study 2}

One purpose of the second study was to determine if the findings of the first study could be replicated in a specific game against one of the top three teams in the conference. Additional purposes included examining the coach's ability to estimate his athletes' self-confidence and anxiety, the athletes' ability to estimate their coach's anxiety and self-confidence, and the relationship of the athletes' estimates to their evaluation of the coach's behavior.

It was hypothesized that the same discrepancies found in Study 1 would exist between the athletes' and the coach's perceptions of coaching behavior and that high cognitive-anxious and low-confident athletes would evaluate coaching behaviors more negatively. Furthermore, it was hypothesized that the coach would not accurately estimate his players' anxiety and self-confidence; athletes would be relatively accurate in predicting their coach's state anxiety and self-confidence; and athletes who perceived the coach to be highly anxious would evaluate the coach's behaviors more negatively. 


\section{Methods}

Subjects. The subject pool for Study 1 was used again for Study 2 . Subjects participated voluntarily and with the assurance of anonymity.

Anxiety Measures. The same CSAI-2 used in Study 1 to assess a more "generalized" competitive state anxiety and self-confidence was used in Study 2. In Study 2, the directions instructed subjects to respond in terms of how they felt "right now."

Coaching Behavior Questionnaire (CBQ). The questionnaire used in Study 1 was used again in Study 2 with the addition of the item "my coach was composed and confident tonight." 'Thus, potential total scores ranged from a high of 88 to a low of 22 .

Procedure. Questionnaires and instructions for conducting the testing were mailed to the same assistant coach who helped in Study 1. Study 2 employed the same procedures as Study 1 to assure confidentiality. The first phase of testing was conducted a half hour prior to the tip-off of a basketball contest against the second-place team in the conference. All athletes completed one CSAI- 2 for themselves and another CSAI-2 for how they perceived their coach would respond concerning his anxiety at that time. The coach completed a CSAI-2 in relation to his own feelings of anxiety.

The second phase was conducted immediately following the basketball game. All subjects completed an evaluation of the coach's behavior for this game. One week later, the coach completed a CSAI-2 for each athlete as he felt she would respond prior to a game against one of the top three teams. Due to the time demands on the coach of responding on 11 questionnaires, this procedure was chosen over his filling out the CSAI-2s prior to a specific game situation. The athletes' generalized anxiety and self-confidence responses from Study 1 were utilized in the statistics examining the coach's ability to estimate his athletes' CSAI-2 scores.

\section{Results and Discussion}

Table 2 contains the mean and standard deviation for each coach and athlete variable measured. Cronbach's alpha reliability for the CBQ was .93. Cronbach's alpha reliabilities for the cognitive anxiety (.80), somatic anxiety (.86), and selfconfidence (.87) subscales of the CSAI-2 were similar to those reported by Martens et al. (1990). Interscale correlations for the cognitive anxiety-somatic anxiety $(r=.54)$, cognitive anxiety-self-confidence $(r=-.60)$, and somatic anxiety-self-confidence $(r=-.51)$ subscales of the CSAI- 2 fell within the ranges reported by Martens et al. (1990).

Independent $t$ tests compared the athletes' mean CSAI-2 scores with norm values (Martens et al., 1990) in basketball player populations. Like the findings in Study 1, no significant differences were found between the sample and the basketball norms, $t(10)<1.47, p>.05$.

The CBQ scores of the coach and the athletes appeared very similar (see Table 2). Unlike Study 1, individual item analysis supported the mean similarity in that the coach's score differed from the athletes' by one standard deviation on only one item and approached one standard deviation on only two items. The item with a standard deviation greater than one was "emotional outbursts from my 
Table 2

\section{Means and Standard Deviations for Athlete and Coach State Anxiety, Self-Confidence, and CBQ Scores}

\begin{tabular}{|c|c|c|c|c|c|c|c|}
\hline \multirow[b]{2}{*}{ Variable } & \multicolumn{2}{|c|}{$\begin{array}{l}\text { Athletes' } \\
\text { score }\end{array}$} & \multicolumn{2}{|c|}{$\begin{array}{l}\text { Coach's est. of } \\
\text { athletes' resp. }\end{array}$} & \multirow{2}{*}{$\begin{array}{l}\text { Coach's } \\
\text { score }\end{array}$} & \multicolumn{2}{|c|}{$\begin{array}{l}\text { Athletes' est. of } \\
\text { coach's resp. }\end{array}$} \\
\hline & $M$ & $S D$ & $M$ & $S D$ & & $M$ & $S D$ \\
\hline State cognitive anxiety & 18.8 & 4.5 & 18.9 & 3.5 & 13 & 22.6 & 6.1 \\
\hline State somatic anxiety & 18.5 & 5.8 & 18.6 & 3.3 & 10 & 30.6 & 4.0 \\
\hline State self-confidence & 25.0 & 5.6 & 23.6 & 4.2 & 28 & 23.5 & 3.4 \\
\hline CBQ & 49.2 & 13.1 & & & 48 & & \\
\hline
\end{tabular}

coach helped me get fired up.' The coach felt his emotional outbursts helped the team whereas the team stated that these outbursts did not serve to motivate them.

At least two possible explanations exist for the disappearance of the discrepancy in item response found in Study 1. First, the coach may have behaved in a way more congruent with what the athletes perceived. Second, the outcome of the game may have influenced the way the athletes responded. According to Smoll and Smith's (1989) model of leadership behaviors in sport, game outcome is a situational factor that affects athletes' perception and recall of coaching behaviors and their evaluative reactions to these same behaviors. The team won, and the excitement of winning such a close and important ball game may have buffered the athletes' actual perceptions of the coaching behaviors while the game was being played.

Contrary to the hypothesis, the athletes' estimates of the coach's pregame state anxiety and self-confidence were not congruent with the self-report of the coach (see Table 2). When the raw scores were converted to a percentile using Martens et al.'s (1990) standardized scores for basketball player populations, the coach's cognitive anxiety self-score placed him in the 11th percentile whereas the athletes' estimations placed him in the 64th percentile. In somatic anxiety and selfconfidence, the coach placed himself in the 8th and 70th percentiles, respectively; the athletes' estimations placed the coach in the 97th and 48th percentiles.

Previous studies found that athletes were somewhat accurate in the estimation of their coach's state anxiety (Kjoss-Hansen, 1983; Martens et al., 1980). The size of the discrepancy found in this study is, therefore, somewhat surprising. The direction of error was consistent across the athlete sample; that is, all athletes in the study perceived the coach to be more anxious and less confident than he perceived himself. A couple of explanations might explain the discrepancy. First, the coach could have failed to accurately report his actual feelings of anxiety and confidence, thereby making his athletes' estimations better representations of his true feelings and thoughts. Second, the coach's self-ratings could be accurate, and some other factor, possibly his coaching behavior or the athletes' own anxiety and confidence levels, may have caused the athletes to perceive the coach as higher in anxiety and lower in confidence than he actually was. 


\section{Relationship Between State CSAl-2 Subcomponents and Evaluation of Coaching Behaviors}

$\begin{array}{lc}\text { Athletes' } & .73^{*} \\ \text { Cognitive anxiety } & .22 \\ \text { Somatic anxiety } & -.13 \\ \text { Self-confidence } & .91^{\star *} \\ \text { Athletes' estimate of coach's } & -.13 \\ \text { Cognitive anxiety } & -.43 \\ \text { Somatic anxiety } & \end{array}$

${ }^{*} p<.01 ;{ }^{* *} p<.001$

As hypothesized, athletes who were high in state cognitive anxiety evaluated coaching behaviors more negatively than did athletes who were low in cognitive anxiety (see Table 3). The five individual items on the CBQ that correlated strongest with athletes' cognitive anxiety were identical to those found in Study 1 to correlate with cognitive anxiety.

The relationship between self-confidence and the evaluation of coaching behaviors found in Study 1 was not supported in Study 2. Again, it is possible that game outcome and the positive, confident feelings that often accompany winning may have influenced the postgame evaluations of coaching behaviors. It is unknown if the same results would have occurred if the team had lost the game.

Although, as stated in Study 1, it would be beneficial for coaches to be able to identify their athletes who are high in cognitive anxiety and low in confidence, correlational analysis indicated that the coach was not an accurate estimator of his players' cognitive anxiety $(r=.25, p>.05)$, somatic anxiety $(r=-.08, p>.05)$, or self-confidence $(r=.36, p>.05)$ prior to competing against one of the top three teams in the conference. Although factors such as change in communication patterns, change in behavior patterns, restlessness, facial expression, and excessive urination have been cited as cues that may indicate an athlete's anxiety level (Hanson \& Gould, 1988), more research needs to be done to identify how coaches can interpret these factors to enhance their ability to accurately estimate their players' anxiety. Hanson and Gould (1988) suggest that the most effective technique for assessing the anxiety levels of athletes is for coaches to take time to get to know their athletes individually so that they can detect deviations from normal behavior patterns for each athlete that may indicate an arousal problem.

Athletes who estimated the coach to be high in state cognitive anxiety also evaluated the coach's game behavior more negatively. If athletes perceive the coach as worried or unsure of his performance capabilities, it is not surprising that they also react more negatively to the coach's behavior. The relationship between the athletes' perception of the coach's anxiety and their perception of his behaviors becomes more interesting given the fact that the athletes in this study may have drastically overestimated their coach's state cognitive anxiety. 
It is possible that some of the factors that influence the athletes' estimation of their coach's anxiety may be the same factors influencing the direction of the coaching-behavior evaluation. The significant correlation between the athletes' own cognitive anxiety and their evaluation of coaching behaviors suggests that the athletes' level of state cognitive anxiety may be one of these factors. The significant correlation between the athletes' cognitive anxiety and the athletes' perceptions of the coach's cognitive anxiety $(r=.65, p<.05)$ supports this supposition. Identifying and modifying factors that influence how athletes evaluate their coaches, such as an athlete's cognitive anxiety, may be helpful in creating a more conducive atmosphere for future coaching effectiveness.

\section{General Discussion}

Across Studies 1 and 2, the cognitive subcomponent of state anxiety appears to be a major variable affecting how a player will evaluate and perceive a coach's game behavior and, according to Study 2, a coach's cognitive anxiety. The five individual items on the CBQ that correlated the highest with cognitive anxiety offer some insight as to the basis of this relationship. The first two items, "my coach made me feel uptight" and "my coach's behavior during the game made me worry about my performance," suggest that a coach's behavior may contribute to the cognitive anxiety that athletes, already high in this aspect, experience during a game.

The next two items, "I got more nervous watching my coach on the sidelines than I did playing the game" and "before and during the game, my coach clearly communicated what he/she expected us to do," add some specificity as to which behaviors in particular may contribute. First, the coach's sideline behavior seems to be affecting his players' cognitive anxiety. Observations of the coach by one of the experimenters during game situations suggest that negative body language such as facial expressions and foot-stomping following athlete errors may be sideline behaviors contributing to the athletes' feeling uptight. These behaviors visibly displayed the coach's disgust in the errors made. The coach should be made aware of the potentially damaging consequences of such behaviors and be given guidelines in modifying nonverbal messages in order to be more supportive and encouraging toward athletes with high cognitive anxiety.

Second, the perception of a coach's inability to clearly communicate may be related to the cognitive anxiety an athlete experiences. Based upon the information gathered, it is not possible to identify if the coach did communicate poorly. $\mathrm{He}$ may have communicated well, as indicated by the correlation with the selfconfident athlete, but the athletes who had high cognitive anxiety could not understand. Perhaps the cognitive anxiety experienced by these athletes creates an "overload" in their capacity to understand information. If so, communication with cognitively anxious athletes might be improved by providing short, simple, and direct verbal cues.

In summary, regarding Smoll and Smith's (1989) model of leadership behaviors in sport, the present results confirm competitive trait anxiety as an individual difference variable mediating athletes' perception and evaluation of coaching behaviors. Both Studies 1 and 2 support the addition of state cognitive anxiety, but not state somatic anxiety, as an individual difference variable that mediates athletes' perception and evaluation of coaching behaviors, and Study 2 
supports the addition of the athletes' perception of the coach's state cognitive anxiety as an individual difference variable. Study 1 also indicated that selfconfidence is a mediator, but Study 2 suggested that game outcome (in this case, winning an important game) may offset the influence of self-confidence on the evaluation of coaching behaviors.

These studies provide preliminary work in testing specific aspects of Smoll and Smith's (1989) model and determining if the CBQ identifies meaningful relationships between anxiety, self-confidence, and the evaluation of coaching behaviors. The results of both studies does indicate merit in the CBQ. However, future research needs to administer the CBQ to a large sample in order to determine if factor structures exist within the questionnaire that could be utilized in future studies to eliminate the danger of Type 1 error, which was present in the individual item analysis of the present studies. The results from this larger sample would also help determine whether the present results are generalizable to other coaches (male and female), teams, and sports.

Future research should also include observation of the coach's behaviors in order to determine if the relationships among anxiety, self-confidence, and athletes' perception and evaluation of coaching behaviors were due to differences in athletes' perceptions of their coach's behavior or to differences in the actual behaviors of the coach. Coaches may actually behave differently toward athletes with high and low levels of anxiety and self-confidence. The results of such studies will determine if an additional mediating arrow should be drawn in Smoll and Smith's (1989) model from athlete individual-difference variables to coach behaviors. In any case, there is merit in further investigating the relationship between anxiety, self-confidence, and coaching-behavior evaluation to determine how to improve coaches' effectiveness in dealing with different types of athletes.

\section{References}

Brown, J.D., Collins, R.L., \& Schmidt, G.W. (1988). Self-esteem and direct versus indirect forms of self-enhancement. Journal of Personality and Social Psychology, 55, 445453.

Gould, D., Krane, V., \& Finch, L. (1990). Factors influencing coaches' ability to predict anxiety levels in their athletes. Unpublished manuscript.

Gould, D., Petlichkoff, L., \& Weinberg, R.S. (1984). Antecedents of, temporal changes in, and relationships between CSAI-2 subcomponents. Journal of Sport Psychology, 6, 289-304.

Hanson, T.W., \& Gould, D. (1988). Factors affecting the ability of coaches to estimate their athletes' trait and state anxiety levels. The Sport Psychologist, 2, 298-313.

Kjoss-Hansen, B. (1983). Prediction of sport competitive state anxiety among coaches and athletes. Dissertation Abstracts International, 44, 3009A. (University Microfilms No. 83-10, 158-159)

Martens, R. (1977). Sport Competition Anxiety Test. Champaign, IL: Human Kinetics.

Martens, R., Rivkin, F., \& Burton, D. (1980). Who predicts anxiety better: Coaches or athletes? In C.D. Nadeau, W.R. Halliwell, K.M. Newell, \& G.C. Roberts (Eds.), Psychology of motor behavior and sport (pp. 84-90). Champaign, IL: Human Kinetics.

Martens, R., Vealey, R., \& Burton, D. (1990). Competitive anxiety in sport. Champaign, IL: Human Kinetics. 
Percival, L. (1971). The coach from the athletes' viewpoint. In J.W. Taylor (Ed.), Proceedings, Symposium on the Art and Science of Coaching (pp. 285-325). Toronto: Fitness Institute.

Shrauger, J.S. (1975). Responses to evaluation as a function of initial self-perceptions. Psychological Bulletin, 82, 581-596.

Smith, R.E., \& Smoll, F.L. (1990). Self-esteem and children's reactions to youth sport coaching behaviors: A field study of self-enhancement processes. Developmental Psychology, 26, 987-993.

Smith, R.E., Smoll, F.L., \& Curtis, B. (1978). Coaching behaviors in Little League baseball. In F.L. Smoll \& R.E. Smith (Eds.), Psychological perspectives in youth sports (pp. 173-201). Washington, DC: Hemisphere.

Smoll, F.L., \& Smith, R.E. (1989). Leadership behaviors in sport: A theoretical model and research paradigm. Journal of Applied Social Psychology, 19, 1522-1551.

Smoll, F.L., Smith, R.E., Barnett, N.P., \& Everett, J.J. (1991). Enhancement of children's self-esteem through social support training for youth sport coaches. Manuscript submitted for publication.

Spielberger, C.D. (1966). Theory and research on anxiety. In C.D. Spielberger (Ed.), Anxiety and behavior (pp. 3-20). New York: Academic Press.

Spielberger, C.D. (1972). Anxiety as an emotional state. In C.D. Spielberger (Ed.), Anxiety: Current trends in theory and research (Vol. 1, pp. 23-49). New York: Academic Press.

Swann, W.B., Jr., Griffin, J.J., Predmore, S.C., \& Gaines, B. (1987). The cognitiveaffective crossfire: When self-consistency confronts self-enhancement. Journal of Personality and Social Psychology, 52, 881-889.

Tesser, A. (1988). Toward a self-evaluative maintenance model of social behavior. In L. Berkowitz (Ed.), Advances in experimental social psychology (Vol. 21, pp. 69-92). San Diego: Academic Press.

Vealey, R.S. (1986). Conceptualization of sport-confidence and competitive orientation: Preliminary investigation and instrument development. Journal of Sport Psychology, 8, 221-246.

Manuscript submitted: January 2, 1992

Revision received: July 14, 1992 